Check for updates

Cite this: RSC Adv., 2018, 8, 39529

\title{
Characterization of immobilized tyrosinase - an enzyme that is stable in organic solvent at $100{ }^{\circ} \mathrm{C} \uparrow$
}

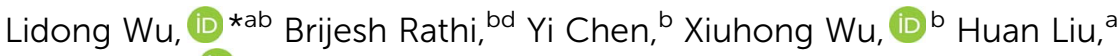 \\ Jincheng Li, (D) anjie Ming ${ }^{c}$ and Gang $\mathrm{Han}^{a}$
}

Tyrosinase is a copper-containing enzyme present in plant and animal tissues, which catalyzes the production of melanin and other pigments. In organic solvent, tyrosinase can convert $\mathrm{N}$-acetyl-Ltyrosine ethyl ester (insoluble in aqueous) to a derivative of L-dopamine (a drug used for the treatment of Parkinson's disease). Thus, the performances of tyrosinase in organic solvent have attracted scientific attention since 1980. In this work, we investigated the stability of immobilized tyrosinase at high temperature in anhydrous organic solvent. Triethylaminoethyl cellulose (TEAE-Cellulose) performed the best out of six immobilization platforms. The dry immobilized tyrosinase became extremely thermostable in organic solvent, and the half-life of the dry immobilized tyrosinase in organic solvent is strongly related to the polarity of the organic solvent than their $\log P$ value. The immobilized tyrosinase loses its activity instantaneously in aqueous solution at $100{ }^{\circ} \mathrm{C}$, but it keeps enzymatic activity within 10 min in hydrophilic methanol and over one month in hydrophobic hexane (log $P$ : 4.66, non-polar) even incubating at $100{ }^{\circ} \mathrm{C}$. This research provides valuable information for the design of new biocatalysts.

Received 11th September 2018 Accepted 2nd November 2018

DOI: $10.1039 / c 8 r a 07559 j$

rsc.li/rsc-advances enzymatic catalysis in organic media have been systematically investigated, ${ }^{\mathbf{9}, \mathbf{1 0}}$ but there is no report about the thermostable behavior of tyrosinase in different pure organic solvents at high temperature.

To study the thermostable behavior of tyrosinase, ${ }^{\mathbf{1 1 , 1 2}}$ the enzyme needs to be incubated in different organic solvents and undergo testing of its activity in the same organic solvent. In this way, the enzyme must be easy to reuse. ${ }^{\mathbf{1 3 , 1 4}}$ As previously reported, immobilization techniques are very efficient method to recycle the enzyme. ${ }^{15-17}$ The enzyme immobilized on a solid carrier can make the enzyme reusability easier. ${ }^{18,19}$ It is one of the key steps to test the thermostability of immobilized enzymes..$^{20-22}$ From previous reports, ${ }^{23,24}$ the adsorption method keeps the original structure of enzyme, ${ }^{25-27}$ but encounters issues with enzyme leaching. Compared with the covalent bonding, ${ }^{28,29}$ entrapment, ${ }^{30-32}$ copolymerization ${ }^{33,34}$ and encapsulation methods, ${ }^{35-37}$ the conditions of the adsorption method are much milder than the other methods. Furthermore, the glass beads, ${ }^{38,39}$ graphene, $^{\mathbf{4 0 , 4 1}}$ magnetic nanoparticles ${ }^{\mathbf{4 2}}$ and metal-organic frameworks (MOFs) ${ }^{\mathbf{4 3 , 4 4}}$ were chosen as the supports to immobilize the enzyme in previous study. In this study, the biocompatible polymers (i.e. cellulose) were utilized as the ideal matrixes due to their low cost, and renewable and biodegradable nature. ${ }^{45-47}$ Besides, we systematically studied different polymers (i.e. cellulose matrixes, Pluronic F68 and poly(styrene-co-divinylbenzene)) and traditional glass beads as enzyme support. ${ }^{48}$

After optimizing the enzyme immobilization material, the organic solvent effect, the position of substituent group and the 

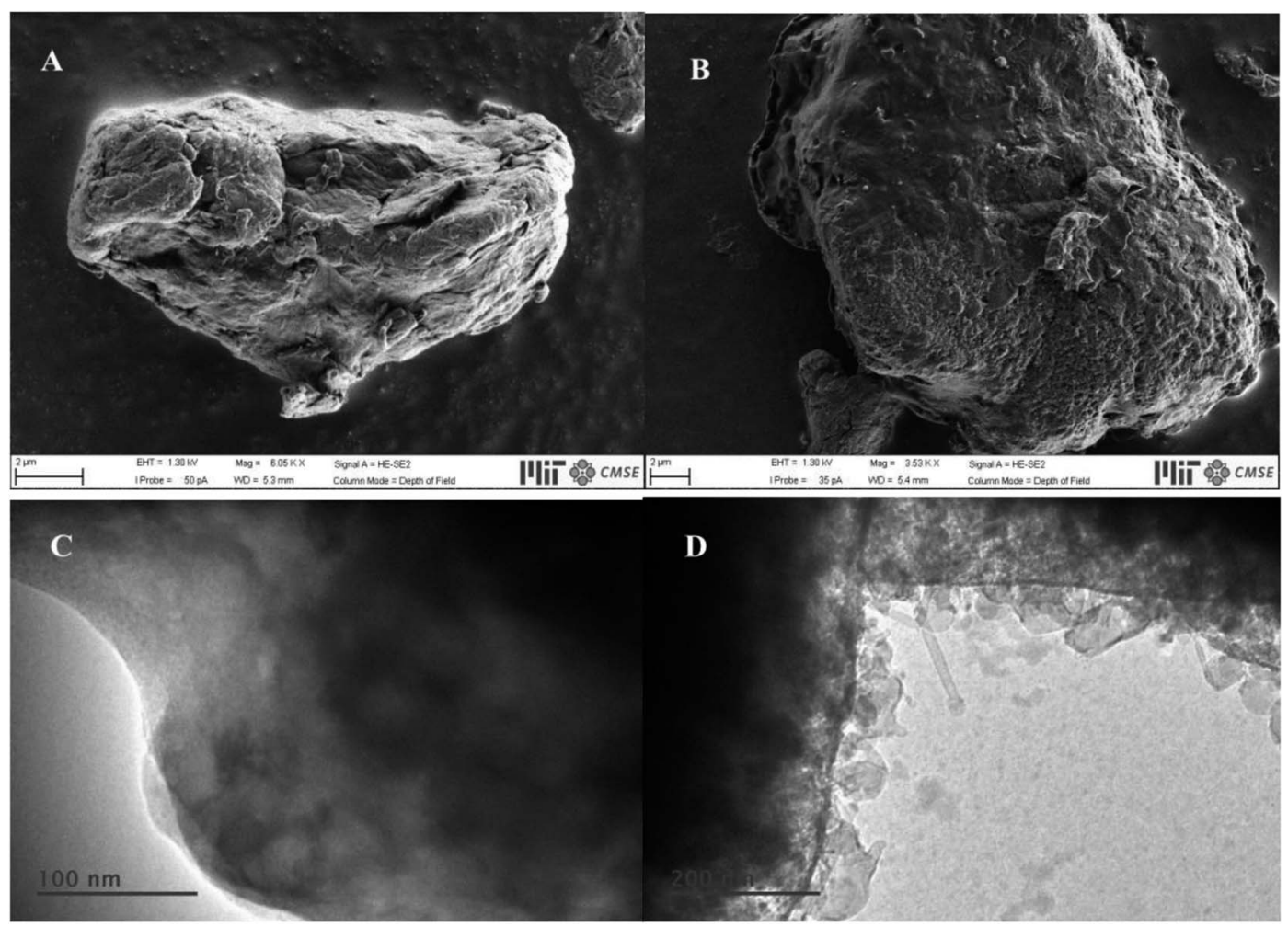

Fig. 1 SEM of (A) triethylaminoethyl cellulose (TEAE-Cellulose) and (B) TEAE-Cellulose with tyrosinase; the TEM of (C) triethylaminoethyl cellulose (TEAE-Cellulose) and (D) TEAE-Cellulose with tyrosinase.

strength of electron-donating substituent group were studied. Furthermore, the activities of immobilized tyrosinase were tested in various hydrophilic and hydrophobic organic solvents at high temperature. This study provided more reasonable and systematical explanation of tyrosinase in organic solvents.

\section{Experimental section}

\section{Materials}

$p$-Cresol, $p$-chlorophenol, $p$-methoxyphenol and other chemicals obtained from Sigma Aldrich (USA) were of the highest purity available. Mushroom Tyrosinase (50 kU, powder) was purchased from Sigma Aldrich (USA) as a solid with a specific activity of 2430 unit per $\mathrm{mg}$ ( 1 unit is defined as the enzyme activity resulting in an increase in absorbance at $280 \mathrm{~nm}$ of 0.001 at pH 6.5 at $25^{\circ} \mathrm{C}$ in a $3 \mathrm{~mL}$ reaction volume containing $\mathrm{L}^{-}$ tyrosine). Poly(styrene-co-divinylbenzene), glass beads, Pluronic F68, cellulose, carboxymethyl cellulose (CM-Cellulose) and triethylaminoethyl cellulose (TEAE-Cellulose) were also purchased from Sigma Aldrich (USA).

\section{Instrumentation}

Scanning electron microscope (SEM) images were obtained through high-resolution SEM (Zeiss Merlin, Germany) with a resolution of $0.8 \mathrm{~nm}$ at $15 \mathrm{kV}$ and $1.4 \mathrm{~nm}$ at $1 \mathrm{kV}$. Transmission electron microscope (TEM) images were obtained from FEI Tecnai Multipurpose TEM (ThermoFisher Scientific, USA). UVVis spectrum was obtained by a UV-Vis Nanodrop 2000C spectroscopy (ThermoFisher Scientific, USA).

\section{Preparation of tyrosinase and immobilization onto TEAE- Cellulose}

Tyrosinase $(6 \mathrm{mg})$ was dissolved in $0.3 \mathrm{~mL}$ of $50 \mathrm{mmol} \mathrm{L}^{-1}$ phosphate buffer ( $\mathrm{pH} 7.0)$, and then $60 \mathrm{mg}$ of cellulose was added. The sticky mixture was spread on a watch glass and left to dry at room temperature. Tyrosinase immobilization onto CM-Cellulose or other materials was prepared following a similar protocol as tyrosinase immobilization onto TEAECellulose.

\section{UV-Vis spectrophotometry detection of the tyrosinase- catalyzed oxidation product}

The time course for tyrosinase-catalyzed oxidation of $p$-cresol in organic solvents was measured by the following procedure: $p$ cresol was dissolved in a given solvent (its concentration: $\left.50 \mathrm{mmol} \mathrm{L}^{-1}\right) .1 \mathrm{~mL}$ of $p$-cresol $\left(50 \mathrm{mmol} \mathrm{L}^{-1}\right)$ in organic solvent was added into a $5 \mathrm{~mL}$ round-bottom flask, followed by addition of $5 \mu \mathrm{L} 50 \mathrm{mmol} \mathrm{L}^{-1}$ phosphate buffer (PBS, $\mathrm{pH}$ 7.0). Then, the immobilized tyrosinase was added. Subsequently, the suspension was stirred by magnetic stirrers at $250 \mathrm{rpm}$ at $25{ }^{\circ} \mathrm{C}$. Aliquots of the liquid were removed and their absorption spectrum was recorded in the range $400-600 \mathrm{~nm}$. The detection procedure of other substrates in a given solvent was the same as $p$-cresol in a given solvent.

\section{Stability of tyrosinase in organic solvent at high temperature}

The immobilized tyrosinase was transferred into a round bottom flask with anhydrous organic solvent under stirring at 
$100{ }^{\circ} \mathrm{C}$. After 1 hour, the anhydrous organic solvent was removed, and then $1 \mathrm{~mL}$ of $p$-cresol in toluene with $5 \mu \mathrm{L}$ $50 \mathrm{mmol} \mathrm{L}^{-1} \mathrm{PBS}$ ( $\mathrm{pH} 7.0$ ) was added. The detection procedure was the same as the time course for tyrosinase-catalyzed oxidation of $p$-cresol in a given solvent.

\section{Results and discussion}

\section{Physical characterization of TEAE-Cellulose and tyrosinase immobilization onto TEAE-Cellulose}

Fig. 1B displays the SEM image of tyrosinase immobilization onto TEAE-Cellulose as compared to the original TEAECellulose (Fig. 1A). There was a significant change in the morphology between the original TEAE-Cellulose and tyrosinase immobilization onto TEAE-Cellulose. The original TEAECellulose had a relative clear edge, and the TEAE-Cellulose with tyrosinase showed an unclear edge, rough surface and more porosity than the original one. Fig. $1 \mathrm{C}$ and D show the TEM image of original TEAE-Cellulose and TEAE-Cellulose with tyrosinase, respectively. The original TEAE-Cellulose surface was very smooth. After tyrosinase immobilization onto TEAECellulose, its surface was rougher than the original one. Pure TEAE-Cellulose has a clear edge from the TEM and SEM images. After tyrosinase is immobilized onto TEAE-Cellulose, TEAECellulose and tyrosinase can cross-link with each other through electrostatic attraction and hydrogen-bond interactions. In this way, the edge of TEAE-Cellulose becomes unclear and rough, and there is some porosity on its surface. Fig. S1A$\mathrm{S} 1 \mathrm{E} \dagger$ display the SEM images of (A) Cellulose, (B) CM-Cellulose, (C) Pluronic F68, (D) poly(styrene-co-divinylbenzene) and (E)
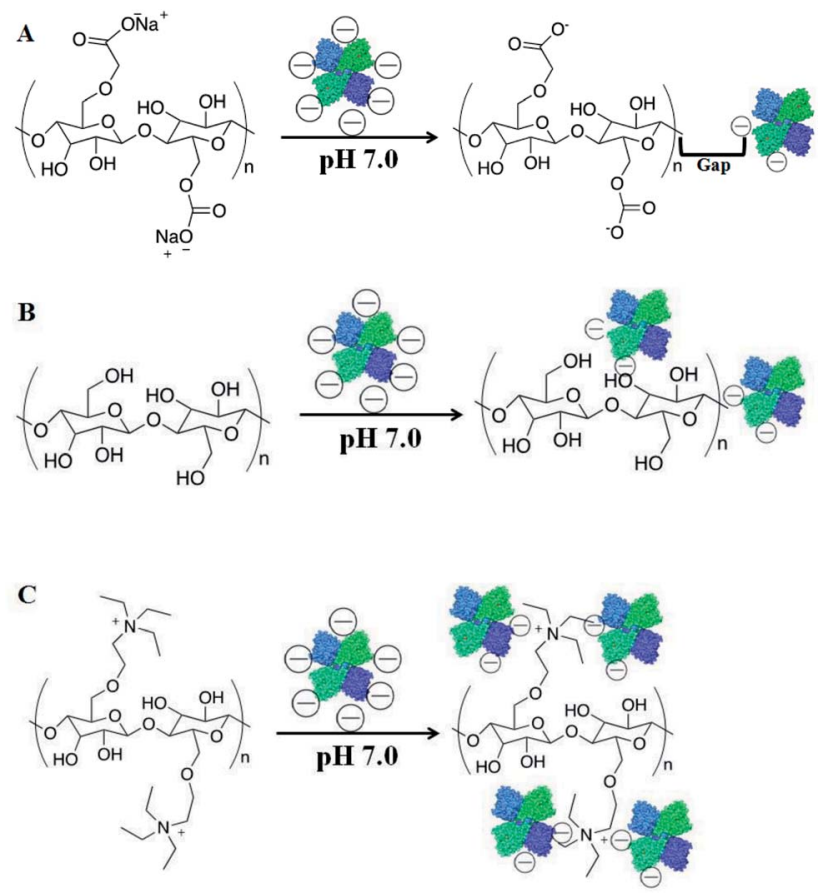

Fig. 2 Schematic diagram describing the mechanism of tyrosinase immobilization onto (A) CM-Cellulose, (B) cellulose and (C) TEAECellulose. glass beads. After immobilization of tyrosinase onto the surface of materials, cellulose, CM-Cellulose and Pluronic F68 morphologies totally changed, and their surfaces became rougher than before. These alterations showed that the tyrosinase had been immobilized onto these materials.

\section{Immobilized tyrosinase biocatalytic ability}

Six kinds of materials were used for the immobilization of tyrosinase: the triethylaminoethyl group of TEAE-Cellulose exhibits positive charge ( $\mathrm{pH}$ 7.0, PBS solution); cellulose, Pluronic F68, poly(styrene-co-divinylbenzene) and glass beads have neutral charges; and the carboxymethyl group of CM-Cellulose has negative charge. As shown in Fig. 2, the TEAE-Cellulose could bind tyrosinase (negative charge at $\mathrm{pH}$ 7.0) due to charge attraction. TEAE-Cellulose is a positively charged resin used in protein purification or separation. It can lock negatively charged protein - tyrosinase onto the carrier by charge attraction and hydrogen-bond interactions. Cellulose can lock part of tyrosinase only through hydrogen-bond interactions. CMCellulose cannot lock tyrosinase like TEAE-Cellulose through charge attraction, but a few of tyrosinase can be locked by hydrogen-bond interactions. The tyrosinase molecules were physically adsorbed onto the surface of Pluronic F68, poly(styrene-co-divinylbenzene) and glass beads. The tyrosinase molecules immobilization efficiency of different materials could be arranged as: TEAE-Cellulose $>$ cellulose $=$ Pluronic F68 $=$ poly(styrene-co-divinylbenzene $)=$ glass beads $>$ CMCellulose.

$p$-Cresol was chosen as the test substrate. The tyrosinase can function in chloroform whereby phenol derivatives can be converted into corresponding stable $o$-quinones. The enzymatic oxidation product of $p$-cresol is 4-methyl-1,2-benzoquinone, and its maximum absorbance peak is at $395 \mathrm{~nm}$. Kinetic analysis of tyrosinase is shown in Fig. 3. The $V_{\mathrm{o}}$ values of immobilized tyrosinase onto TEAE-Cellulose, cellulose, poly(styrene-codivinylbenzene), Pluronic F68, glass beads and CM-Cellulose were $6.7 \times 10^{-2}, 5.5 \times 10^{-2}, 4.4 \times 10^{-2}, 3.6 \times 10^{-2}, 2.8 \times$

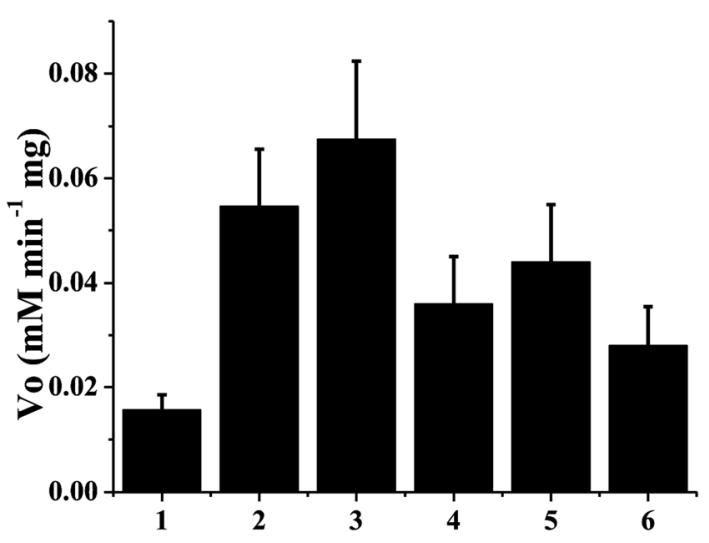

Fig. $3 V_{\circ}$ values of tyrosinase molecular immobilization onto $\mathrm{CM}$ Cellulose, cellulose, TEAE-Cellulose, Pluronic F68, poly(styrene-codivinylbenzene) and glass beads catalyzed oxidations of $p$-cresol as substrate in chloroform. $p$-Cresol concentration for these reactions is $50 \mathrm{mmol} \mathrm{L}^{-1}$. Error bar means standard deviation. 
Table 1 The activity of tyrosinase immobilization onto TEAE-Cellulose was detected in organic solvent (i.e. $\mathrm{CH}_{2} \mathrm{Cl}_{2}, \mathrm{CCl}_{4}$ and toluene)

\begin{tabular}{|c|c|c|c|c|}
\hline$p$-Cresol & $V_{\mathrm{o}}\left(\mathrm{mmol} \mathrm{L}^{-1} \min ^{-1}\right)$ & Std & $\log P$ & $\begin{array}{l}\text { Viscosity } 10^{-3} \\
\text { Pa S }\end{array}$ \\
\hline Acetonitrile & - & - & -0.34 & 0.34 \\
\hline Tetrahydrofuran & - & - & 0.46 & 0.46 \\
\hline 1-Octanol & $<8.3 \times 10^{-4}$ & - & 3 & 7.4 \\
\hline tert-Butyl methyl ether & $8.3 \times 10^{-4}$ & $2.6 \times 10^{-4}$ & 0.94 & 0.36 \\
\hline $\mathrm{CH}_{2} \mathrm{Cl}_{2}$ & $1.5 \times 10^{-3}$ & $2.5 \times 10^{-4}$ & 1.25 & 0.42 \\
\hline Chlorobenzene & $5.7 \times 10^{-2}$ & $5.0 \times 10^{-3}$ & 2.84 & 0.75 \\
\hline $\mathrm{CHCl}_{3}$ & $6.1 \times 10^{-2}$ & $4.6 \times 10^{-3}$ & 1.97 & 0.54 \\
\hline $\mathrm{CCl}_{4}$ & $6.3 \times 10^{-2}$ & $3.0 \times 10^{-3}$ & 2.83 & 0.9 \\
\hline Toluene & $6.7 \times 10^{-2}$ & $1.4 \times 10^{-3}$ & 2.73 & 0.55 \\
\hline
\end{tabular}

$10^{-2}$ and $1.5 \times 10^{-2} \mathrm{mmol} \mathrm{L}^{-1} \mathrm{~min}^{-1}$, respectively. The $V_{\mathrm{o}}$ value of immobilized tyrosinase onto TEAE-Cellulose was the highest among those onto CM-Cellulose, cellulose, Pluronic F68, poly(styrene-co-divinylbenzene) and glass beads, and the $V_{\mathrm{o}}$ value of immobilized tyrosinase onto CM-Cellulose was the lowest among these materials. The results were consistent with the mechanism shown in Fig. 2. The TEAE-Cellulose was demonstrated to be the best supporting platform for tyrosinase and it was chosen as the immobilization material in the following research work.

\section{Immobilization enzyme kinetics in organic solvent}

After optimizing the tyrosinase immobilization platform, the stability of immobilized tyrosinase was systematically assessed in different organic solvents. Organic solvents can affect the structure of enzymes at the secondary, tertiary and quaternary levels. ${ }^{7}$ It is important to note how organic solvents affect the immobilized tyrosinase activity. From Table 1, the data demonstrates that the immobilized tyrosinase was completely inactive in hydrophilic solvents viz. acetonitrile $(\log P,-0.34)$ and tetrahydrofuran $(\log P, 0.46)$. This can be attributed to the fact that the hydrophilic solvents could strip the essential water from tyrosinase's hydration "shell" (hence deactivate the enzyme). Moreover, the immobilized tyrosinase had biocatalytic ability in hydrophobic solvent i.e. tert-butyl methyl ether $(\log P$, 0.94), methylene chloride $(\log P, 1.25)$, chloroform $(\log P, 1.97)$, carbon tetrachloride $(\log P, 2.83)$, chlorobenzene $(\log P, 2.84)$ and toluene $(\log P, 2.73)$. Octanol-water partition coefficient $(\log P)$ is used in QSAR studies and rational chemical design as a measurement of molecular hydrophobicity. Our results suggested that the hydrophobicity of organic solvent played an important role in tyrosinase efficiency. As the hydrophobicity of organic solvents increased, most of the biocatalytic efficiency of the immobilized tyrosinase increased. There is an exception to this rule. 1-Octanol is categorized as a hydrophobic solvent and the value of $\log P$ is relatively high (achieved 3 , similarly with toluene and carbon tetrachloride), but the $V_{\mathrm{o}}$ value of the immobilized tyrosinase in 1-octanol is relatively low (less than $\left.8.3 \times 10^{-4}\right)$. In this case, the viscosity of 1 -octanol achieves as high as $7.4 \times 10^{-3} \mathrm{~Pa} \mathrm{~s}$, and the mass-transfer rate of substrate in 1-octanol is very slow. This might be one of the most important parameters in determining the biocatalytic efficiency of the immobilized tyrosinase. As a result, toluene was chosen as the solvent to test the immobilized tyrosinase activity.

\section{The biocatalytic efficiency of the immobilized tyrosinase for different substituent groups of para-cresol isomers in hydrophobic organic solvent}

After optimizing the immobilized tyrosinase solvent conditions, the relationship between the structure of the substrate and the activity of the immobilized tyrosinase was systematically studied. How the substituent group position (three isomers of $p$ cresol) influenced the selectivity of the immobilized tyrosinase in toluene was examined. Table 2 shows that the $V_{\mathrm{o}}$ value for tyrosinase in the toluene medium, using $p$-cresol as substrate, was 8.7-fold higher than those obtained with $m$-cresol as substrate and more than 30-fold higher than those with $o$-cresol as substrate (the $V_{\mathrm{o}}$ number was too small to check). The orthosubstituent group was not significantly catalyzed by the immobilized tyrosinase because such substrates sterically hinder the accessibility of the phenolic hydroxyl moiety to the active-site of tyrosinase. The steric influence of the para substituent group of phenol for the biocatalysis of tyrosinase was less than that of meta or ortho substituents.

It was essential to know how the different para substituent groups influence the catalytic efficiencies of the immobilized tyrosinase. Different para-substituent groups of phenol were tested in toluene. Table 3 shows that the $V_{\mathrm{o}}$ value of tyrosinase

Table 2 The bioactivity of tyrosinase was tested for different substituent sites in different solvent (i.e. $\mathrm{CH}_{2} \mathrm{Cl}_{2}, \mathrm{CCl}_{4}$ and toluene)

\begin{tabular}{|c|c|c|c|c|c|c|}
\hline Substrate & $p$-Cresol $\left(V_{\mathrm{o}}\right)$ & $p$-Cresol (Std) & $m$-Cresol $\left(V_{\mathrm{o}}\right)$ & $m$-Cresol (Std) & $o$-Cresol $\left(V_{\mathrm{o}}\right)$ & $o$-Cresol (Std) \\
\hline Toluene & $6.7 \times 10^{-2}$ & $1.4 \times 10^{-3}$ & $7.7 \times 10^{-3}$ & $2.2 \times 10^{-4}$ & $<8.3 \times 10^{-4}$ & - \\
\hline Chlorobenzene & $5.7 \times 10^{-2}$ & $5.0 \times 10^{-3}$ & $6.5 \times 10^{-3}$ & $1.9 \times 10^{-5}$ & $<8.3 \times 10^{-4}$ & - \\
\hline $\mathrm{CHCl}_{3}$ & $6.1 \times 10^{-2}$ & $4.6 \times 10^{-3}$ & $7.0 \times 10^{-3}$ & $1.2 \times 10^{-4}$ & $<8.3 \times 10^{-4}$ & - \\
\hline $\mathrm{CCl}_{4}$ & $6.3 \times 10^{-2}$ & $3.0 \times 10^{-3}$ & $7.2 \times 10^{-3}$ & $1.2 \times 10^{-4}$ & $<8.3 \times 10^{-4}$ & - \\
\hline
\end{tabular}


Table 3 The bioactivity of tyrosinase was detected for six kinds of para-substituents of phenol in toluene

\begin{tabular}{llllr}
\hline Substrate & $V_{\mathrm{o}}\left(\mathrm{mmol} \mathrm{L}^{-1} \mathrm{~min}^{-1}\right)$ & Std & $\log K_{\text {ow }}$ & $\begin{array}{l}\text { Solubility in } \\
\text { water }\left(\mathrm{mol} \mathrm{m}^{-3}\right)\end{array}$ \\
\hline$p$-Methyl & $6.7 \times 10^{-2}$ & $1.4 \times 10^{-3}$ & 1.96 & 184.9 \\
$p$-Ethyl & $4.1 \times 10^{-2}$ & $3.2 \times 10^{-3}$ & 2.50 & 65.3 \\
$p$-Propyl & $2.8 \times 10^{-2}$ & $2.1 \times 10^{-3}$ & 3.20 & 12.7 \\
$p$-Chloro & $2.1 \times 10^{-2}$ & $1.8 \times 10^{-3}$ & 2.40 & 210.0 \\
$p$-Bromo & $9.2 \times 10^{-3}$ & $8.5 \times 10^{-4}$ & 2.59 & 85.54 \\
$p$ - $t$-Butyl & $2.0 \times 10^{-3}$ & $2.0 \times 10^{-5}$ & 3.65 & 3.861
\end{tabular}
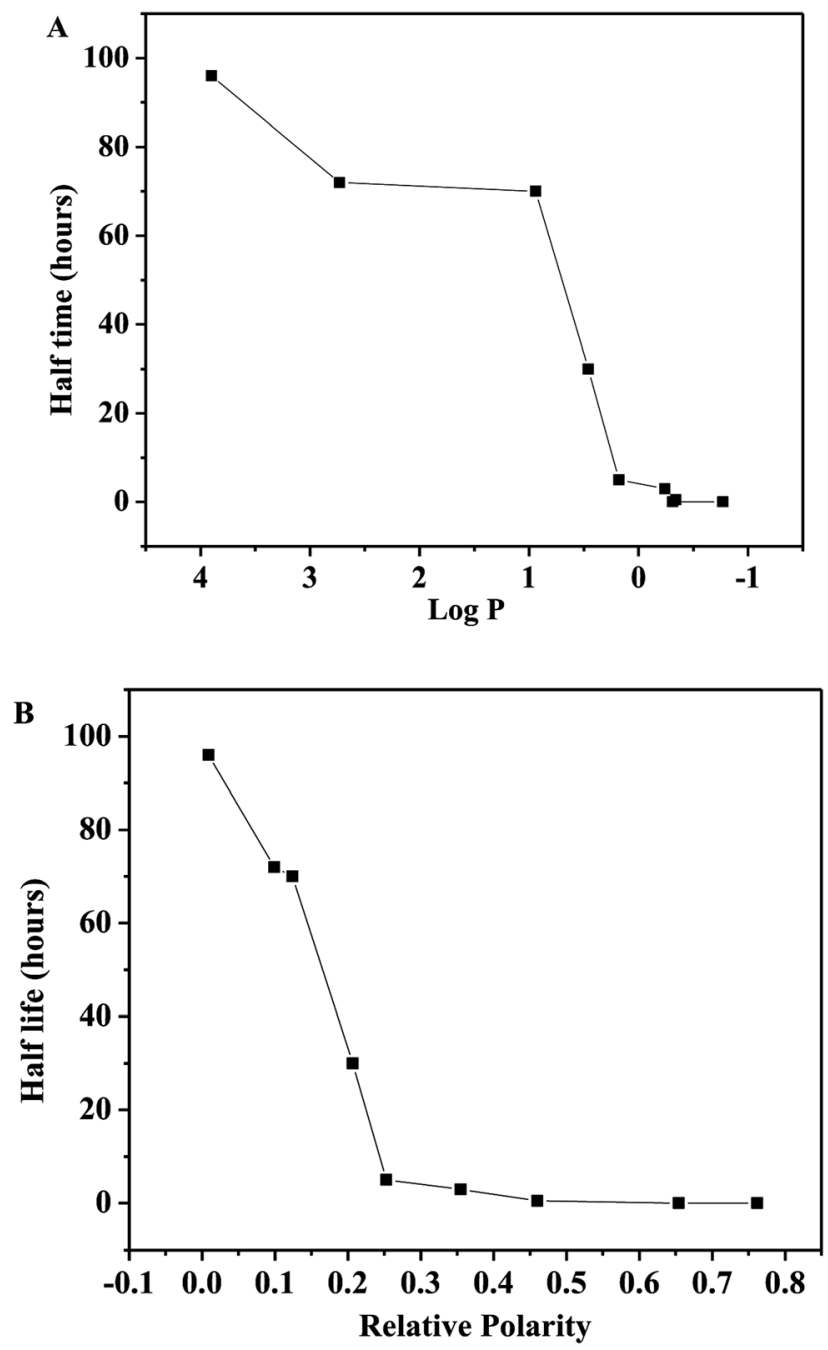

Fig. 4 (A) The half-life of the immobilized tyrosinase vs. the $\log P$ values of the organic solvent, (B) the half-life of the immobilized tyrosinase vs. the relative polarity values of the organic solvent. The organic solvent from right to left is methanol, ethanol, acetonitrile, acetone, methyl acetate, tetrahydrofuran, methyl t-butyl ether, toluene and hexane.

biocatalysis for para substituent were: $p$-methyl $>p$-ethyl $>p$ propyl $>p$-chloro $>p$-bromo $>p$-t-butyl. The methyl, ethyl, propyl and $t$-butyl groups are electron-donating substituent groups. By increasing the electron-donating ability and the steric size of para-substituents, the corresponding $V_{\mathrm{o}}$ value of the immobilized tyrosinase decreased. It indicated that the tyrosinase activity was related to the electron-donating ability and steric size of the substitute. In contrast, $p$-chloro and $p$ bromo are electron-withdrawing substituent groups; their corresponding $V_{\mathrm{o}}$ value of the immobilized tyrosinase decreased with their deactivating ability. The conclusion was consistent with the quantitative assessment of enzymatic catalysis by Dordick et al. ${ }^{49}$

After optimizing the immobilized platform, the substrate and the solvent, the behavior of tyrosinase in anhydrous organic solvent at high temperature was studied. In this way, the immobilized tyrosinase was treated as a synthetic catalyst. Nine kinds of anhydrous organic solvents were used for storing the immobilized tyrosinase at $100{ }^{\circ} \mathrm{C}$. The nine anhydrous organic solvents are methanol $(\log P,-0.77$; relative polarity, 0.762), ethanol $(\log P,-0.31$; relative polarity, 0.654), acetonitrile $(\log P,-0.34$; relative polarity, 0.46$)$, acetone $(\log P,-0.24$; relative polarity, 0.355), methyl acetate $(\log P, 0.18$; relative polarity, 0.762), tetrahydrofuran $(\log P, 0.46$; relative polarity, $0.207)$, methyl $t$-butyl ether $(\log P, 0.94$; relative polarity, 0.124$)$, toluene $(\log P, 2.73$; relative polarity, 0.099) and hexane $(\log P$, 3.9; relative polarity, 0.009). As shown in Fig. 4, the half-life of the immobilized tyrosinase is strongly related to the relative polarity value of the storage solvent than their $\log P$ values. After the immobilized tyrosinase is immersed in anhydrous hexane at $100{ }^{\circ} \mathrm{C}$ for 96 hours, the immobilized tyrosinase still retains over $60 \%$ activity. Conversely, the immobilized tyrosinase loses the activity immediately in water at $100{ }^{\circ} \mathrm{C}$. This indicated that the immobilized tyrosinase could keep its catalytic structure and be used as a synthetic catalyst in anhydrous organic solvent at high temperature. This research provides a lot of information for mimicking enzyme reactions.

\section{Conclusion}

Triethylaminoethyl cellulose (TEAE-Cellulose) was selected as the best immobilization platform from six kinds of materials. Compared with traditional immobilization materials (glass beads), the activity of tyrosinase immobilization onto TEAECellulose was two times higher than that of immobilization onto glass beads. The immobilized tyrosinase showed potential to be a catalyst in organic solvent without water. The half-life of the dry immobilized tyrosinase in organic solvent was strongly related to the polarity of the solvent rather than the $\log P$ value of the organic solvent. This research could be valuable for the design of new biocatalysts. 


\section{Conflicts of interest}

There are no conflicts to declare.

\section{Acknowledgements}

This study was supported by China Scholarship Council, the National Natural Science Foundation of China (No. 21307161, 61335008 and 61874137). Authors would like to thank Alexander M. Klibanov who gave lots of suggestion in experiment details.

\section{References}

1 K. V. N. Esguerra and J. P. Lumb, Selectivity in the Aerobic Dearomatization of Phenols: Total Synthesis of Dehydronornuciferine by Chemo- and Regioselective Oxidation, Angew. Chem., Int. Ed., 2018, 57(6), 1514-1518.

2 D. Ma, Z. C. Tu, H. Wang, L. Zhang, N. He and D. J. McClements, Mechanism and kinetics of tyrosinase inhibition by glycolic acid: a study using conventional spectroscopy methods and hydrogen/deuterium exchange coupling with mass spectrometry, Food Funct., 2017, 8(1), 122-131.

3 Z. Ashraf, M. Rafiq, H. Nadeem, M. Hassan, S. Afzal, M. Waseem, K. Afzal and J. Latip, Carvacrol derivatives as mushroom tyrosinase inhibitors; synthesis, kinetics mechanism and molecular docking studies, PLoS One, 2017, 12(5), 1-7.

4 M. Rolff, J. Schottenheim, H. Decker and F. Tuczek, Copper$\mathrm{O}_{2}$ reactivity of tyrosinase models towards external monophenolic substrates: molecular mechanism and comparison with the enzyme, Chem. Soc. Rev., 2011, 40(7), 4077-4098.

5 R. Z. Kazandjian and A. M. Klibanov, Regioselective Oxidation of Phenols Catalyzed by Polyphenol Oxidase in Chloroform, J. Am. Chem. Soc., 1985, 107(19), 5448-5450.

6 A. M. Klibanov, Enzyme-Catalyzed Processes in OrganicSolvents, Ann. N. Y. Acad. Sci., 1987, 501, 129.

7 S. G. Burton, Biocatalysis with Polyphenol Oxidase a Review, Catal. Today, 1994, 22(3), 459-487.

8 P. V. Iyer and L. Ananthanarayan, Enzyme stability and stabilization - aqueous and non-aqueous environment, Process Biochem., 2008, 43(10), 1019-1032.

9 A. Zaks and A. M. Klibanov, The Effect of Water on Enzyme Action in Organic Media, J. Biol. Chem., 1988, 263(17), 8017-8021.

10 E. Rubio, A. Fernandezmayorales and A. M. Klibanov, Effect of the Solvent on Enzyme Regioselectivity, J. Am. Chem. Soc., 1991, 113(2), 695-696.

11 D. A. Cowan and R. Fernandez-Lafuente, Enhancing the functional properties of thermophilic enzymes by chemical modification and immobilization, Enzyme Microb. Technol., 2011, 49(4), 326-346.

12 R. Fernandez-Lafuente, Stabilization of multimeric enzymes: Strategies to prevent subunit dissociation, Enzyme Microb. Technol., 2009, 45(6-7), 405-418.
13 R. Plothe, I. Sittko, F. Lanfer, M. Fortmann, M. Roth, V. Kolbach and J. C. Tiller, Poly(2-ethyloxazoline) as Matrix for Highly Active Electrospun Enzymes in Organic Solvents, Biotechnol. Bioeng., 2017, 114(1), 39-45.

14 F. S. Liao, W. S. Lo, Y. S. Hsu, C. C. Wu, S. C. Wang, F. K. Shieh, J. V. Morabito, L. Y. Chou, K. C. W. Wu and C. K. Tsung, Shielding against Unfolding by Embedding Enzymes in Metal-Organic Frameworks via a de Novo Approach, J. Am. Chem. Soc., 2017, 139(19), 6530-6533.

15 U. Guzik, K. Hupert-Kocurek and D. Wojcieszynska, Immobilization as a Strategy for Improving Enzyme Properties-Application to Oxidoreductases, Molecules, 2014, 19(7), 8995-9018.

16 K. Min and Y. J. Yoo, Recent progress in nanobiocatalysis for enzyme immobilization and its application, Biotechnol. Bioprocess Eng., 2014, 19(4), 553-567.

17 M. M. Talukder, T. Takeyama, Y. Hayashi, J. C. Wu, T. Kawanishi, N. Shimizu and C. Ogino, Improvement in enzyme activity and stability by addition of low molecular weight polyethylene glycol to sodium bis(2-ethyl-L-hexyl) sulfosuccinate/isooctane reverse micellar system, Appl. Biochem. Biotechnol., 2003, 110(2), 101-112.

18 R. C. Rodrigues, C. Ortiz, A. Berenguer-Murcia, R. Torres and R. Fernandez-Lafuente, Modifying enzyme activity and selectivity by immobilization, Chem. Soc. Rev., 2013, 42(15), 6290-6307.

19 E. T. Hwang and M. B. Gu, Enzyme stabilization by nano/ microsized hybrid materials, Eng. Life Sci., 2013, 13(1), 4961.

20 K. Labus, A. Turek, J. Liesiene and J. Bryjak, Efficient Agaricus bisporus tyrosinase immobilization on cellulosebased carriers, Biochem. Eng. J., 2011, 56(3), 232-240.

21 M. Bilal, T. Rasheed, Y. Zhao, H. M. N. Iqbal and J. Cui, "Smart" chemistry and its application in peroxidase immobilization using different support materials, Int. J. Biol. Macromol., 2018, 119, 278-290.

22 C. Silva, M. Martins, S. Jing, J. Fu and A. Cavaco-Paulo, Practical insights on enzyme stabilization, Crit. Rev. Biotechnol., 2018, 38(3), 335-350.

23 V. M. Balcao and M. M. D. C. Vila, Structural and functional stabilization of protein entities: state-of-the-art, Adv. Drug Delivery Rev., 2015, 93, 25-41.

24 D. Brady and J. Jordaan, Advances in enzyme immobilisation, Biotechnol. Lett., 2009, 31(11), 1639-1650.

25 D. M. Liu, J. Chen and Y. P. Shi, Tyrosinase immobilization on aminated magnetic nanoparticles by physical adsorption combined with covalent crosslinking with improved catalytic activity, reusability and storage stability, Anal. Chim. Acta, 2018, 1006, 90-98.

26 P. Wang, C. Qi, Y. Yu, J. Yuan, L. Cui, G. Tang, Q. Wang and X. Fan, Covalent Immobilization of Catalase onto Regenerated Silk Fibroins via Tyrosinase-Catalyzed CrossLinking, Appl. Biochem. Biotechnol., 2015, 177(2), 472-485.

27 T. Jesionowski, J. Zdarta and B. Krajewska, Enzyme immobilization by adsorption: a review, Adsorption, 2014, 20(5-6), 801-821. 
28 C. Garcia-Galan, A. Berenguer-Murcia, R. FernandezLafuente and R. C. Rodrigues, Potential of Different Enzyme Immobilization Strategies to Improve Enzyme Performance, Adv. Synth. Catal., 2011, 353(16), 2885-2904.

29 K. Hernandez and R. Fernandez-Lafuente, Control of protein immobilization: Coupling immobilization and site-directed mutagenesis to improve biocatalyst or biosensor performance, Enzyme Microb. Technol., 2011, 48(2), 107-122.

30 P. Garcia, I. A. Ramallo and R. L. Furlan, Reverse Phase Compatible TLC-Bioautography for Detection of Tyrosinase Inhibitors, Phytochem. Anal., 2017, 28(2), 101-105.

31 L. V. Sigolaeva, S. Y. Gladyr, A. P. Gelissen, O. Mergel, D. V. Pergushov, I. N. Kurochkin, F. A. Plamper and W. Richtering, Dual-stimuli-sensitive microgels as a tool for stimulated spongelike adsorption of biomaterials for biosensor applications, Biomacromolecules, 2014, 15(10), 3735-3745.

32 H. Yagar and S. Kocaturk, Comparison of some biochemical properties of artichoke polyphenol oxidase entrapped in alginate-carrageenan and alginate gels, Artif. Cells, Nanomed., Biotechnol., 2014, 42(4), 268-273.

33 K. Abu-Rabeah, B. Polyak, R. E. Ionescu, S. Cosnier and R. S. Marks, Synthesis and characterization of a pyrrolealginate conjugate and its application in a biosensor construction, Biomacromolecules, 2005, 6(6), 3313-3318.

34 H. B. Yildiz, E. Sahmetlioglu, A. E. Boyukbayram, L. Toppare and Y. Yagci, Immobilization of tyrosinase and alcohol oxidase in conducting copolymers of thiophene functionalized poly(vinyl alcohol) with pyrrole, Int. J. Biol. Macromol., 2007, 41(3), 332-337.

35 Y. J. Jiang, W. Y. Sun, Y. P. Wang, L. H. Wang, L. Y. Zhou, J. Gao, Y. He, L. Ma and X. Zhang, Protein-based inverse opals: A novel support for enzyme immobilization, Enzyme Microb. Technol., 2017, 96, 42-46.

36 S. K. S. Patel, S. H. Choi, Y. C. Kang and J. K. Lee, Large-scale aerosol-assisted synthesis of biofriendly $\mathrm{Fe}_{2} \mathrm{O}_{3}$ yolk-shell particles: a promising support for enzyme immobilization, Nanoscale, 2016, 8(12), 6728-6738.

37 D. Yang, X. Y. Wang, J. F. Shi, X. L. Wang, S. H. Zhang, P. P. Han and Z. Y. Jiang, In situ synthesized $\mathrm{rGO}-\mathrm{Fe}_{3} \mathrm{O}_{4}$ nanocomposites as enzyme immobilization support for achieving high activity recovery and easy recycling, Biochem. Eng. J., 2016, 105, 273-280.

38 S. J. Brooks, L. Coulombel, D. Ahuja, D. S. Clark and J. S. Dordick, Expanding the Scope of Biocatalysis:
Oxidative Biotransformations on Solid-Supported Substrates, Adv. Synth. Catal., 2008, 350(10), 1517-1525.

39 J. C. Warrington and B. A. Saville, Tyrosinase inactivation in organic solvents, Biotechnol. Bioeng., 1999, 65(3), 325-333.

40 Z. Qu, W. Na, X. Liu, H. Liu and X. Su, A novel fluorescence biosensor for sensitivity detection of tyrosinase and acid phosphatase based on nitrogen-doped graphene quantum dots, Anal. Chim. Acta, 2018, 997, 52-59.

41 Y. Wang, F. Zhai, Y. Hasebe, H. Jia and Z. Zhang, A highly sensitive electrochemical biosensor for phenol derivatives using a graphene oxide-modified tyrosinase electrode, Bioelectrochemistry, 2018, 122, 174-182.

42 H. Vaghari, H. Jafarizadeh-Malmiri, M. Mohammadlou, A. Berenjian, N. Anarjan, N. Jafari and S. Nasiri, Application of magnetic nanoparticles in smart enzyme immobilization, Biotechnol. Lett., 2016, 38(2), 223-233.

43 X. Lu, X. Wang, L. Wu, L. Wu, R. Dhanjai, L. Fu, Y. Gao and J. Chen, Response Characteristics of Bisphenols on a MetalOrganic Framework-Based Tyrosinase Nanosensor, ACS Appl. Mater. Interfaces, 2016, 8(25), 16533-16539.

44 X. Lian, Y. Huang, Y. Zhu, Y. Fang, R. Zhao, E. Joseph, J. Li, J. P. Pellois and H. C. Zhou, Enzyme-MOF Nanoreactor Activates Nontoxic Paracetamol for Cancer Therapy, Angew. Chem., 2018, 57(20), 5725-5730.

45 P. Zucca, R. Fernandez-Lafuente and E. Sanjust, Agarose and Its Derivatives as Supports for Enzyme Immobilization, Molecules, 2016, 21(11), 1577-1598.

46 E. P. Cipolatti, A. Valerio, R. O. Henriques, D. E. Moritz, J. L. Ninow, D. M. G. Freire, E. A. Manoel, R. FernandezLafuente and D. de Oliveira, Nanomaterials for biocatalyst immobilization - state of the art and future trends, $R S C$ Adv., 2016, 6(106), 104675-104692.

47 J. J. Virgen-Ortiz, S. Peirce, V. G. Tacias-Pascacio, V. CortesCorberan, A. Marzocchella, M. E. Russo and R. FernandezLafuente, Reuse of anion exchangers as supports for enzyme immobilization: Reinforcement of the enzymesupport multiinteraction after enzyme inactivation, Process Biochem., 2016, 51(10), 1391-1396.

48 O. Barbosa, C. Ortiz, A. Berenguer-Murcia, R. Torres, R. C. Rodrigues and R. Fernandez-Lafuente, Strategies for the one-step immobilization-purification of enzymes as industrial biocatalysts, Biotechnol. Adv., 2015, 33(5), 435-456.

49 K. Ryu and J. S. Dordick, Quantitative and Predictive Correlations for Peroxidase Catalysis in Organic Media, Biotechnol. Tech., 1992, 6(3), 277-282. 